\title{
Safety and Efficacy of Azathioprine as a Second Line Therapy for Primary Immune Thrombocytopenic Purpura
}

\author{
Bishesh Sharma Poudyal, ${ }^{1}$ Binaya Sapkota, ${ }^{2}$ Gentle Sunder Shrestha, ${ }^{3}$ Sujan Thapalia, ${ }^{4}$ Bishal Gyawali, \\ Sampurna Tuladhar ${ }^{6}$ \\ 'Clinical Hematology and Bone Marrow Transplant Unit, Government of Nepal Civil Service Hospital, Kathmandu, Nepal, \\ ${ }^{2}$ Department of Pharmacology, Civil Service Hospital, Kathmandu,Nepal, ${ }^{3}$ Intensive Care Unit, Tribhuwan University Teaching \\ Hospital, Kathmandu, Nepal, ${ }^{4}$ Mid Western Regional Hospital, Surkhet, Nepal, ${ }^{5}$ Department of Clinical Oncology and \\ Chemotherapy, Nagoya University Hospital, Nagoya, Japan, 'Department of Pathology and Clinical Hematology, Civil \\ Service Hospital, Kathmandu, Nepal.
}

\section{ABSTRACT}

Introduction: Immune thrombocytopenic purpura remains common blood disease in Nepal. Azathioprine is an oral immunosupressive medicine which has been used widely in various autoimmune disease and solid organ transplant patients. It is inexpensive, easily available and well tolerated medicine. This study was carried out to evaluate efficacy and safety of azathioprine as a second line medicine for primary ITP patients who were refractory to steroid therapy.

Methods: The observational, pre-post study was conducted at Government of Nepal Civil Service Hospital, Kathmandu from January to October 2014. Twenty four primary ITP patients who were steroid refractory were treated with Azathioprine. Patients were termed steroid refractory if platelet counts were less than $30,000 / \mathrm{ul}$ on day $21^{\text {st }}$ of steroid therapy. From day 22 onwards oral azathioprine $2 \mathrm{mg} / \mathrm{kg}$ was started and steroids were tapered $10 \mathrm{mg} /$ week and stopped. Platelet counts of more than $30000 / \mathrm{ul}$ after one month of stopping steroid, while still on azathioprine, were termed response to azathioprine. Platelet count of more than $100,000 / \mathrm{ul}$ was termed complete response. The associations among age, gender, duration and platelets counts were analyzed by chi square test and Fisher's exact test (when individual cell frequency was less than 5). The comparison of platelets counts among the start and day 90 of Azathioprine therapy was performed by the paired t-test.

Results: The study showed that there was not significant association among age and gender of the patients and their platelets count on the start of Azathioprine therapy ( $\mathrm{p}$ value 0.354 and 0.725 respectively) and on day 90 of Azathioprine therapy ( $p$ value 0.082 and 0.762 respectively). The duration-wise comparisons of platelets count on both the start and day 90 of Azathioprine therapy were significant ( $\mathrm{p}$ values 0.029 and 0.008 respectively). The paired comparison among platelets count on the start and day 90 of Azathioprine therapy was highly significant ( $p$ value 0.000 ).

Conclusions: The study showed the therapeutic implication of azathioprine in ITP patients. It also showed that efficacy of azathioprine was comparable with other modes of treatment. In low income countries like Nepal azathioprine can be considered as second line treatment for steroid refractory ITP patients.

Keywords: immune thrombocytopenic purpura; autoimmune disease; steroids; azathioprine; Nepal.

Correspondence: Dr. Bishesh Sharma Poudyal, Clinical Hematology and Bone Marrow Transplant Unit, Government of Nepal Civil Service Hospital, Kathmandu, Nepal. Email: drbishesh78@hotmail. com, Phone: +977-9802044244. 


\section{INTRODUCTION}

Immune thrombocytopenic purpura (ITP) is an autoimmune disease characterized by isolated thrombocytopeni (platelet count $<100,000 /$ ul) resulting from accelerated clearance and destruction of antibody coated platelets by tissue macrophages, predominately in the spleen. ${ }^{1}$ Antiplatelet antibodies also target antigens on megakaryocytes and proplatelets, variably suppressing platelet production. ${ }^{2}$ ITP has been broadly divided into two groups, primary and secondary ITP. Causes of primary ITP is unknown, whereas ITP associated with infection, lymphoproliferative disease, drug ingestion, collagen vascular disease and other malignancies are termed secondary. ${ }^{3}$

Although considered uncommon blood disease in the western countries, ITP remains common blood disease in Nepal (unpublished data from civil service hospital). Steroids are conventional first-line therapy for adults $\mathrm{ITP}^{4}$ and have long remained the standard of care, however, its doses and duration has not been properly addressed.

The management of patients who fail corticosteroids is challenging, as there have been no comparative trials of treatment options in this setting. ${ }^{5}$ Over the years some have advocated on the use of rituximab, eltrombopag and splenectomy. ${ }^{6}$ Splenectomy, although curative in $60-65 \%$ patients, is a surgical procedure with mortality rate of 0.2. Rituximab, a potent anti- CD20 antibody and eltrombopag, a thrombopoetin receptor agonist, is an effective but expensive modes of treatment for the patients whose average annual income is less than 700 USD. ${ }^{5}$

Azathioprine is an oral immunosupressive medicine which has been used widely in various autoimmune disease and solid organ transplant patients. ${ }^{7}$ It is inexpensive, easily available and well tolerated medicine. This study was carried out to evaluate efficacy and safety of azathioprine as a second line medicine for primary ITP patients who were refractory to steroid therapy.

\section{METHODS}

The observational, pre-post study was conducted at Government of Nepal Civil Service Hospital, Kathmandu from January to October 2014. Twenty four primary ITP patients who were steroid refractory were treated with Azathioprine. The study was ethically approved by the Civil Service Hospital Ethical Review Board.

All the primary immune thrombocytopenic purpura (ITP) patients who were above 14 years of age were included by applying principles of simple random sampling technique. Patients with secondary immune thrombocytopenic purpura (ITP) cases and below 14 years of age were excluded from the study. The ITP patients who refused to participate in the study were also excluded.

Patients were termed steroid refractory if platelet counts were less than $30,000 / \mathrm{ul}$ on day $21^{\text {st }}$ of steroid therapy (three days of $1 \mathrm{gm}$ of inj. Methyprednisolone followed by oral prednisolone $1 \mathrm{mg} / \mathrm{kg} /$ day for 18 days). From day 22 onwards oral azathioprine $2 \mathrm{mg} / \mathrm{kg}$ was started and steroids were tapered $10 \mathrm{mg} /$ week and stopped. Platelet counts of more than 30000/ul after one month of stopping steroid, while still on azathioprine, were termed response to azathioprine. Platelet count of more than $100,000 / u l$ was termed complete response. Liver function test, renal function test, leukopenia, hair loss were monitored closely for all patients.

Patient demographic data were collected for all the patients for the total duration of Azathioprine therapy. Their platelets counts were taken on the start and on day 90 of Azathioprine therapy. Data were then analyzed via statistical package for the social sciences (SPSS) version 22. The associations among age, gender, duration and platelets counts were analyzed by chi square test and Fisher's exact test (when individual cell frequency was less than 5). The comparison of platelets counts among the start and day 90 of Azathioprine therapy was performed by the paired t-test. A $p$ value less than 0.05 was considered statistically significant at $95 \%$ confidence interval. The power of the study was considered to be $80 \%$.

\section{RESULTS}

The study showed that $50 \%$ patients were young (from 16 to 35 years) with mean age 39.08 years. Female patients were more compared to males. The patients were treated for one month and 5 months $(16.7 \%$ each) with mean duration of treatment 5.058 months (Table 1).

\begin{tabular}{|c|c|}
\hline Study characteristics & n (\%) \\
\hline $\begin{array}{l}\text { Age of the patient (in years) } \\
39.08 \pm 20.295 \text { ) }\end{array}$ & (Mean \pm SD: \\
\hline$<=15$ & $1(4.2)$ \\
\hline $16-25$ & $6(25.0)$ \\
\hline $26-35$ & $6(25.0)$ \\
\hline $36-45$ & $4(16.7)$ \\
\hline $46-55$ & $2(8.3)$ \\
\hline $56-65$ & $2(8.3)$ \\
\hline $66-75$ & $1(4.2)$ \\
\hline $76-85$ & $1(4.2)$ \\
\hline $86+$ & $1(4.2)$ \\
\hline
\end{tabular}




\begin{tabular}{|lc|} 
Gender of the patient & $7(29.2)$ \\
Male & $17(70.8)$ \\
Demale & (Mean \pm SD: \\
$5.058 \pm 4.0534)$ & \\
1.0 & $4(16.7)$ \\
2.0 & $2(8.3)$ \\
2.5 & $1(4.2)$ \\
3.0 & $3(12.5)$ \\
3.2 & $1(4.2)$ \\
4.0 & $1(4.2)$ \\
5.0 & $4(16.7)$ \\
5.5 & $1(4.2)$ \\
6.0 & $1(4.2)$ \\
7.0 & $3(12.5)$ \\
12.0 & $1(4.2)$ \\
13.2 & $1(4.2)$ \\
17.0 & $1(4.2)$ \\
\hline
\end{tabular}

The study showed that there was not significant association among age of the patients and their platelets count on the start of Azathioprine therapy $(p$ value 0.354$)$. The mean platelet count on the start of Azathioprine therapy was 8958.33. There was also insignificant association of gender of the patients and their platelets counts on the start of Azathioprine therapy ( $p$ value 0.725 ) (Table 2 ).

There was insignificant association among age of the patients and their platelets count on day 90 of Azathioprine therapy ( $p$ value 0.082). The mean platelet count on day 90 of Azathioprine therapy was 63875 . The gender-wise association of platelet counts with day 90 of Azathioprine therapy was also non-significant ( $p$ value 0.762 ) (Table 3 ).

The duration-wise comparisons of platelets count on both the start and day 90 of Azathioprine therapy were significant with $p$ values 0.029 and 0.008 respectively. The paired comparison among platelets count on the start and day 90 of Azathioprine therapy was highly significant ( $p$ value 0.000 ) (Table 4).

\begin{tabular}{|c|c|c|c|c|c|c|c|}
\hline \multirow{2}{*}{$\begin{array}{l}\text { Age of the } \\
\text { patient (in } \\
\text { years) }\end{array}$} & \multicolumn{5}{|c|}{ Platelets count on day 21 while on steroids (Day when Azathioprine started) } & \multirow{2}{*}{ Total } & \multirow{2}{*}{$P$ value } \\
\hline & $<=2000$ & $2001-6000$ & $6001-10000$ & $10001-14000$ & $14001+$ & & \\
\hline$<=15$ & 0 & 0 & 0 & 0 & 1 & 1 & \\
\hline $16-25$ & 0 & 3 & 2 & 1 & 0 & 6 & \\
\hline $26-35$ & 0 & 0 & 3 & 0 & 3 & 6 & \\
\hline $36-45$ & 0 & 2 & 1 & 1 & 0 & 4 & \\
\hline $46-55$ & 1 & 0 & 1 & 0 & 0 & 2 & 0.354 \\
\hline $56-65$ & 0 & 0 & 1 & 0 & 1 & 2 & \\
\hline $66-75$ & 0 & 0 & 1 & 0 & 0 & 1 & \\
\hline $76-85$ & 0 & 1 & 0 & 0 & 0 & 1 & \\
\hline $86+$ & 0 & 0 & 1 & 0 & 0 & 1 & \\
\hline \multicolumn{8}{|c|}{ Gender of the patient } \\
\hline Male & 0 & 1 & 4 & 1 & 1 & 7 & \multirow{2}{*}{0.725} \\
\hline Female & 1 & 5 & 6 & 1 & 4 & 17 & \\
\hline
\end{tabular}




\begin{tabular}{|c|c|c|c|c|c|c|c|c|}
\hline \multirow{2}{*}{$\begin{array}{l}\text { Age of the } \\
\text { patient (in } \\
\text { years) }\end{array}$} & \multicolumn{8}{|c|}{ Platelets count on day 90 of Azathioprine therapy } \\
\hline & ${ }_{30000}=$ & $\begin{array}{l}30001 \\
60000\end{array}$ & $\begin{array}{r}60001 \\
90000\end{array}$ & $\begin{array}{l}-90001 \\
120000\end{array}$ & $\begin{array}{l}120001 \\
150000\end{array}$ & $270001+$ & Total & $P$ value \\
\hline$<=15$ & 1 & 0 & 0 & 0 & 0 & 0 & 1 & \multirow{9}{*}{0.082} \\
\hline $16-25$ & 4 & 1 & 0 & 0 & 1 & 0 & 6 & \\
\hline $26-35$ & 1 & 3 & 2 & 0 & 0 & 0 & 6 & \\
\hline $36-45$ & 0 & 2 & 1 & 1 & 0 & 0 & 4 & \\
\hline $46-55$ & 0 & 0 & 2 & 0 & 0 & 0 & 2 & \\
\hline $56-65$ & 0 & 1 & 1 & 0 & 0 & 0 & 2 & \\
\hline $66-75$ & 0 & 0 & 0 & 0 & 0 & 1 & 1 & \\
\hline $76-85$ & 0 & 0 & 1 & 0 & 0 & 0 & 1 & \\
\hline $86+$ & 0 & 1 & 0 & 0 & 0 & 0 & 1 & \\
\hline \multicolumn{9}{|c|}{ Gender of the patient } \\
\hline Male & 1 & 3 & 3 & 0 & 0 & 0 & 7 & \multirow{2}{*}{0.762} \\
\hline Female & 5 & 5 & 4 & 1 & 1 & 1 & 17 & \\
\hline
\end{tabular}

Table 4. Duration-wise comparison of Platelets count on the start and day 90 of Azathioprine therapy.

Study variable 1

Duration of disease (in month)

Duration of disease (in month)

Platelets count on day 21 while on

steroids (Day when Azathioprine started)

\section{Study variable 2}

$P$ value

Platelets count on day 21 while on steroids (Day when Azathioprine started)

Platelets count on day 90 of Azathioprine therapy

0.029

Platelets count on day 90 of Azathioprine therapy

0.000

\section{DISCUSSION}

Our study, probably the first of its kind from Asia, showed azathioprine as a potential second line treatment option for immune thrombocytopenic purpura. In a low income country like Nepal, azathioprine remains an attractive treatment choice as other modes of treatment like rituximab, thrombopoietin mimetic agents and anti-D are very expensive. Few uncontrolled case series of selected patients have reported that approximately $20 \%$ of patients may achieve complete response with a daily dose of azathioprine 1-2 mg/kg for several months. ${ }^{8,9}$ In our study, $75 \%$ patients showed overall response and $16 \%$ achieved complete remission.

Azathioprine causes decreased numbers of circulating Band T-lymphocytes, reduced immunoglobulin synthesis, diminished interleukin (IL)-2 secretion, and inhibition of the intracellular signaling downstream of T-cell costimulation involving CD28-mediated pathways. ${ }^{10,11,12}$
The most common side effects of Azathioprine at doses typically used in the treatment of rheumatic diseases include gastrointestinal intolerance, hepatotoxicity, bone marrow suppression, and infection. Two patients in the present study complained of decreased appetite after starting azathioprine, both of them improved after decreasing the dose of azathioprine. Four patients developed mild transaminitis which resolved later on. Myelosupression was not noted in any patients.

Although a benign disease, steroid refractory ITP is a real challenge to the hematologist in low income countries. The International Consensus report lists more than 10 second-line therapeutic options, including splenectomy, without indicating a preference. ${ }^{6}$ Most of these patients were young and in otherwise excellent health condition but have a very low platelet counts. Although critical bleeding is rare, even with most 
severe thrombocytopenia each patient should receive a special care and brief history of the profession should be sought because with the same platelet count some (e.g. mechanic) may have high risk of bleeding while the other may not have not a high risk of bleeding (office clerk).

In a recent 10-year study of 310 patients in whom treatment was generally used only at platelet counts less than $30000 \times 10^{9} / \mathrm{L}$, only one hemorrhagic death occurred. Major bleeding, including spontaneous intracerebral hemorrhage $(\mathrm{ICH})$, occurs predominantly in patients with platelet counts less than $20000 \times 10^{9} / \mathrm{L}$ (generally less than $10000 \times 10^{9} / \mathrm{L}$ ). ${ }^{13}$ Based on these and several other studies, our goal was to maintain platelet count of more than $30,000 \times 10^{9} / \mathrm{L}$. None of the patients, who responded on azathioprine, demonstrated bleeding manifestation.

Rituximab has been widely used in immune thrombocytopenic purpura. Responses are usually noted within 4 to 8 weeks after the first infusion but may occur as late as 4 months. A complete or partial remission occurs in $25 \%$ to $50 \%$ of patients; many complete responses are durable ( $>1$ year). ${ }^{14,15}$ Rituximab is costly and was not a feasible option for majority of our patients. Splenectomy is another option, approximately $85 \%$ of patients attain a hemostatic response after splenectomy and two thirds achieve a durable response. ${ }^{16}$ The major known long-term risk of splencetomy is overwhelming bacterial sepsis, which occurs in less than $1 \%$ of adults with uncomplicated ITP. ${ }^{17}$ Recently thrombopoeitin mimetic agents have gained popularity in ITP patients ${ }^{18}$ but again this mode of treatment is very expensive and not within the affordability of the average Nepali population.

The study was a single-center study and the sample size might not be the exact representatives of the whole case so as to generalize the findings of the study. However, it can represent a valuable database for similar type of multi-centric trial with large sample size.

\section{CONCLUSIONS}

The study showed the therapeutic implication of azathioprine in ITP patients. It also showed that efficacy of azathioprine was comparable with other modes of treatment. In low income countries like Nepal azathioprine can be considered as second line treatment for steroid refractory ITP patients.

\section{ACKNOWLEDGEMENTS}

The authors would like to express their gratitude to all the ITP patients who came to Civil Service Hospital OPD for treatment and who were willing to participate in the study. We are also very much grateful to all the members from Hematology Department of the hospital for their valuable contribution throughout research work.

\section{REFERENCES}

1. Cines DB, McMillian R. Pathogenesis of chronic immune thrombocytopenic purpura. Curr Opin Hematol. 2007;14(5):511-4.

2. McMillian R, Wang L, Tomer A, Nichol J, Pistillo J. Supression of in vitro megakaryocytes production by antiplatelets autoantibodies from adult patients with Chronic ITP. Blood. 2004;103(4):1364-9.

3. Ayesh MH, Alawneh K, Khassawneh B, Khader Y, Kasaabeh A. Adult primary and secondary immunr thrombocytopenic purpura: a comparative analysis of characteristics and clinical course. Clin Appl Thromb Hemost. 2013;19(3): 327-30.

4. Chriiatiane DT, David CC. Thrombocytopenia caused by immunoloic platelet destruction. In Wintrobe Clinical Haematology $13^{\text {th }}$ edition Volume 2: Lippincott and Wilkins 2009;1293-1313.

5. Walleded G, Bertrand G, Douglas BC, James BB. How I treat immune thrombocytopenia: the choice between splenectomy or medical therapy as a second line treatment. Blood. 2012;120:960-9.
6. Proven D, Stasi R, Newland AC, et al. International consensus report on the investigation and management of primary immunethrombocytopenia. Blood. 2010;115(2):168-86.

7. Maltzman J, Koretzky G. Azathioprine: old drug new actions. J Clin Invest. 2003;111:1122-4.

8. Vesely SK, Perdue JJ, Rizvi MI, Terrel DR, George JN. Management of adult patients with idiopathic thrombocytopenic purpura after failure of splenectomy. A systemic review. Ann Int Med. 2004;140:112-20.

9. Pizzuto J, Ambritz R. Therapeutic experience on 934 adults with idiopathic thrombocytopenic purpura:multicenter trial of cooperative latin American group on hemostatis and thrombosis. Blood. 1984;64:1179-83.

10. McKendry RJR. Pruine analogues. In: Second Line Agents in the Treatment of Rheumatic Diseases, Dixon J, Furst BE (Eds), Marcel Decker, New York, USA, 1991.

11. Trotter JL, Rodey GE, Gebel HM. Azathioprine decreases suppressor T cells in patients with multiple sclerosis. NEJM. 1982;306:65. 
12. Bacon PA, Salmon M. Modes of action of second line agents. Scand J rheumatol. 1987;64(Suppl):17

13. Vianelli N, Valdre L, Fiacchini M, et al. Long term follow up of idiopathic thrombocytopenic purpura in 310 patients. Haematologica. 2001;86:504-9.

14. Stasi R, Pagano A, Stipa E, Amadori S. Rituximab chimeric anti CD 20 monoclonal antibody treatment for adults with chronic idiopathic thrombocytopenic purpura. Blood. 2001;98:952-7.

15. Cooper N, Stasi R, Cunningham Randles S, et al. The efficacy and saftey of B cell depletion with anti CD 20 monoclonal antibody in adults with chronic immune thrombocytopenia purpura. Brit J Haematol. 2004;125:232-9.
16. Kojouri K, Vesely SK, Terrel DR, George JN. Splenectomy for adult patients with idiopathic thrombocytopenic purpura: a systemic review to assess long term platelet count responses, prediction of response and surgical complication. Blood 2004;104:2623-34.

17. Lortan JE. Management of asplenic patients. Br. J Haematol. 1993;84:566-9.

18. Ivy A, Jefry W, Vinod P. Bleeding and mortality outcomes in ITP clinical trials: A review of thrompoietin mimetics data. Am J Haematol. 2012; 87:984-7. 